\title{
Agro photovoltaic: feasibility of synergistic system in the sugarcane bioenergy sector
}

\author{
Agricultura 4.0: Origem e características no mundo e no Brasil
}

Mario Antonio Stefani ${ }^{1 \S} \mathbb{D}$; João Felema²

Received: nov. 01, 2021

Accepted: jan. 05, 2022

${ }^{1}$ MBA USP ESALQ - São Carlos, SP, Brasil

${ }^{2} \mathrm{PhD}$ Applied Economics. Professor Agribusiness Management FUP/UnB -Prudentópolis, PR, Brasil

${ }^{\S}$ corresponding author: mastefani7@gmail.com

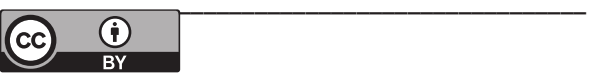

This is an Open Access article distributed under the terms of the Creative Commons Attribution License, which permits unrestricted use, distribution, and reproduction in any medium, provided the original work is properly cited.

\begin{abstract}
A feasibility analysis of the agro photovoltaic approach applied in the sugarcane energy sector is presented. A tailored architecture of photovoltaic implementation was designed to be installed above and on the same area of sugarcane plot without reduction of the planted area, respecting the agronomic requirements of the crop. Were analyzed mutual influences, necessary adjustments in crop handling, life cycle management, cross effects on agro-industrial costs and yields, potential savings, gains by additional electricity generation and improved economic results from synergies. The combined cross effects were applied in a hypothetical sugar-energy plant in the central region of the state of São Paulo, using typical figures and parameters of the 2019/2020 harvest season, based on updated sectorial reports, and using similarly typical parameters of photovoltaic plants. The greatest operational gain was due to the optimization and cost sharing with the existing electricity generation on the thermal plant drive by biomass, and the highest relative incremental cost resulted from the photovoltaic installation, adapted conveniently to the special management and handling practices required by sugarcane crop. The approach proved economically feasible, respecting the agronomic conditions of the crop and the optimized use of the electric cogeneration infrastructure drive by biomass. The approach resulted on a significant increase in the revenues of energy cogeneration and the joint economic margin. The average return on investment period was around 12 years, and 9 years using specific promoted funding lines. The main feasibility constraints and check items are those related to the minimum negotiated average price of electricity, and to the capital expenditure (CAPEX) of the adapted photovoltaic architecture installation, strongly linked to the currency exchange ratio.
\end{abstract}

Keywords: cogeneration; optimization of land use; renewable energy; solar energy.

Resumo: O presente trabalho avaliou a viabilidade do emprego da abordagem agro fotovoltaica no ramo sucroenergético da cana. É apresentada uma proposta de arquitetura de implementação fotovoltaica a ser instalada sobre a mesma área do canavial, sem redução da área plantada, respeitando as condicionantes agronômicas da lavoura. Foram analisadas as influências mútuas, os ajustes necessários no manejo da cultura, os efeitos em custos e rendimentos agroindustriais, as economias decorrentes das sinergias encontradas, refletindo em ganhos econômicos pela geração elétrica adicional. Os efeitos cruzados foram combinados e aplicados em uma hipotética usina sucroenergética, na região central do estado de São Paulo, utilizando parâmetros típicos da safra 2019/2020, de acordo com os relatórios setoriais atualizados, e similarmente, parâmetros típicos de usinas fotovoltaicas. O maior ganho operacional foi oriundo da otimização do compartilhamento dos custos com a geração elétrica por biomassa e o maior incremental relativo de custo decorreu da instalação fotovoltaica, modificadas convenientemente ao manejo da cana. A abordagem se mostrou economicamente viável, respeitando as condicionantes agronômicas da lavoura e a otimização do uso da infraestrutura da cogeração elétrica por biomassa, permitindo um aumento significativo das receitas da cogeração de energia e da margem econômica combinada. O prazo médio de retorno do investimento ficou ao redor de 12 anos, capital próprio, e 9 anos utilizando financiamento em linhas específicas de fomento. Os principais condicionantes da viabilidade são aqueles relacionados ao preço médio negociado da energia elétrica, e ao despesas de capitais (CAPEX) da arquitetura da instalação fotovoltaica adaptada, este fortemente atrelado à taxa de câmbio.

Palavras-chave: cogeração; otimização do uso da terra; energia renovável; energia solar. 


\section{Introduction}

The present work refers to the Agro Photovoltaic approach and evaluate its use in the sugarcane energy sector. In short, Agro Photovoltaics (APV) is the strategy of using the same area of land that is being used for agricultural production, also used by photovoltaic energy generation, concomitantly, carefully elaborated, and synergistically explored ${ }^{[1]}$.

To evaluate APV applicability in Brazilian Sugarcane sector, it is necessary to understand its genesis. The first proposal for the approach aimed at agricultural and photovoltaic production in the same area was made by Goetzberger and Zastrow ${ }^{[2]}$ in Germany. The original concept proposed the careful installation of photovoltaic collectors above a potato crop plot. The proposal aimed to allow farmers additional sources of income, envisioning the scarcity of land for agricultural occupations in Europe and the growing demands of renewable energy and state sponsored incentives for its use. This proposal began to have supporters in France, basically driven by the same reason ${ }^{[3]}$.

According to Marrou et al. ${ }^{[4],[5]}$, as well as Adeh et al. ${ }^{[6]}$, Harinarayana and Vasavi ${ }^{[7]}$, Essam et al. ${ }^{[8]}$, the APV is aimed at the use of the same areas already occupied by agriculture for the production of photovoltaic energy, and could result in a significant land use efficiency, by combined yield gain. It was demonstrated that there are beneficial effects resulting from the microclimate, including water retention, reduction of foliage temperature and transpiration, which allow in some cases increased crop productivity.

Schindele et al. ${ }^{[9]}$, Dias et al. ${ }^{[10]}$, Weselek et al. ${ }^{[1]}$ conclude that due to agronomic effects, there is an optimal proportion area ratio or coverage allocated to photovoltaic modules, and at the same time to avoid dichotomy with food production. The area ratio cannot be too large, due effects of reducing the insolation caused by the modules shadow, probable crop yield penalty due to the reduction of biomass production via photosynthesis path. On the other hand, cannot be too small, as the incomes of electrical cogeneration become marginal. Those authors eventually concluded that the approach would be feasible by seeking some methodologies and criteria and thus proposed a series of good practices guidelines for optimized land use.

Trommsdorff ${ }^{[11]}$ and Weselek et al. ${ }^{[1]}$ argued that specific crop management practices should be observed. Photovoltaic modules should be planned and installed carefully, so as not to hinder crop management, especially the harvesting practices performed by automatic machines, as well as irrigation practices.

Bigaton et al. ${ }^{[12]}$ and Bigaton et al. ${ }^{[13]}$ state that in the sugar ethanol energy sector, the land cost, whether leased or not, has been increased along last years, raising some concerns and warnings due effects suggesting that the discussion of optimized land use is coming. As has occurred in countries with agricultural expansion frontier limitations, the combined use of land for simultaneous agricultural and energy production will be soon included in the strategic discussion of agribusiness in Brazil.

It is a common practice in Brazil that sugarcane mills and energy plants already have electricity thermal generation infrastructure by burning biomass and all the regulatory clearance to access the distribution grid network, and this cogeneration is the item that brings the greatest margin of financial return ${ }^{[13]}$. This fact suggests that if they have additional electrical cogeneration increased, higher returns may occur than those derived only from the biomass burning energy plants, due scale gains coming from synergistic effects of combined use.

The present work sought to adapt the methodologies, techniques and conclusions derived from the studies of APV initiatives taking place abroad, thought the eyes, circumstances and interest of the Brazilian sugar and bioenergy sector. The methodology used here verified the existence of economic feasibility considering the agronomic, operational, systemic effects that induce mutual influences on the combined activity. In this path, the feasibility-promoting factors, items to be pursued as decision flags were presented.

\section{Materials and Methods}

For the application of APV technology in the sugarcane energy sector, the methodologies and techniques used in APV experiments existing abroad are employed. Specific items are adapted, both from the technical agronomic point of view, and from the perspective of the economic feasibility of innovation projects.

As shown in the works of Goetzberger and Zastrow ${ }^{[2]}$, Dupraz et al. ${ }^{[3]}$, Trommsdorff ${ }^{[11]}$, Dinesh 
and Pearce ${ }^{[14]}$, Amaducci et al. ${ }^{[15]}$, Barron-Gafford et al. ${ }^{[16]}$, Weselek et al. ${ }^{[1]}$ and Schindele et al. ${ }^{[9]}$, the combined use of an area of land for both agricultural use and simultaneous photovoltaic energy production require careful technical and economic analysis. The general methodology consists of systematically analyzing the mutual influences and consequences of the presence of photovoltaic modules positioned above the crop, that is, their effects on physiology, microclimate, and crop management, changes on agricultural practices, without forgetting the cross effects, and specific needs. This approach drives the designs of a photovoltaic implementation architecture that allows exploring these synergies and cross effects, seeking to maximize mutual gains.

For the analysis of the proposed technical and economic feasibility, some answers to the aspects related to the plant, environment or microclimate, management and system should be derived.

The first aspect to drive the project is related with the plant bio domain, if the agricultural crop, sugarcane, would be shade tolerant. The positioning of photovoltaic modules above the crop produces shade and, therefore, in thesis would cause the reduction of direct incidence of solar radiation. Thus, in principle they could affect the generation of biomass through the photosynthetic path. To evaluate this influence, practical results were sought, or at least agronomic evidence, derived from similar cases.

Dupraz et al.. ${ }^{[3]}$, Marrou et al. ${ }^{[17]}$, Marrou et al. ${ }^{[4],[5]}$ and Weselek et al. ${ }^{[1]}$ present several evidence that in certain crops not only resist the shade well but also present productivity gains.

Poorter et al. ${ }^{[18]}$ systematically analyzed the effects of light intensity and its periodicity on 70 different species, and classified the plants into classes: those that, when submitted to small shadows, showed positive or negative effects on their productivity. All these results were obtained in species adapted to temperate farming conditions in Europe, with little data on tropical crops such as sugarcane.

Due to the absence of specific studies on the APV approach combined with sugarcane culture, looking for the effects on photosynthesis and the effects of microclimate, were necessary search for evidence about the probable weights of influences, effects, and consequences, observing results in the literature.

Rodrigues et al. ${ }^{[19]}$ contains a detailed study on the sugarcane physiology, reporting several practical aspects of management, productivity, and discussing influences of temperature, humidity, water, and thermal stress. In the work of Sage et al. ${ }^{[20]}$ a study was conducted regarding main factors affecting the photosynthetic efficiency of sugarcane.

Dupraz et al. ${ }^{[3]}$ when presenting its methodology, pointed out similarities with the methods and results derived from agroforestry systems. This observation was used here in a proposed approach that proved promising for the case of sugarcane. For sugarcane crop, it was possible to obtain results from agroforestry arrangements, such as those obtained by Schwerz et al. ${ }^{[21]}$, shown ahead.

Another aspect of the project requires to address the microclimatic effects that could induce benefits on the crop. The presence of photovoltaic modules produces changes in the microclimate under them and thus induce temperature, humidity and evaporation changes. Marrou et al. ${ }^{[4]},{ }^{[5]}$ presented results from combined effects that could induce benefits to several species, either by increasing humidity, reducing thermal stress, and mainly by reducing energy expenditure, due to the reduction of energy consumption by the savings of what would be spent on foliar perspiration.

For crop management issues, where several practical aspects can ruin the best intentions, the author sought to know the actual practices in visiting a mill plant, in the northwest region of the state of São Paulo, near Araçatuba city. Practical aspects were discussed about soil preparation, sugarcane plot formation, fertilization, irrigation, harvesting, transshipment, milling, electrical cogeneration, agronomic and systemic management. All these factors were discussed and considered in the analysis of influences and mutual effects on the APV approach.

For the sugarcane energy case, an important question was whether simultaneous photovoltaic cogeneration would allow systemic or operational gains and confirm whether they would induce benefits or difficulties to the combined activity. In the state of São Paulo, it is a common practice sugar mills also have thermal electric cogeneration by burning biomass, sugarcane bagasse, both using own residual or also coming from third parties. Therefore, the most evident opportunity for operational synergies is configured. It is important to note that if the plant already sells its electricity surplus, has adequate electricity generation infrastructure, has personnel and management 
capabilities derived of this generation, and all necessary and required systems configuration allowing energy injection in the network for distribution. And a very important aspect: already has the necessary regulatory and legal clearance. An increase in the energy produced by photovoltaic means, in the same plant, and using the same sensors, management and control infrastructure, can allow to earn additional gains and returns using the same investment already made.

In Brazil there are incentives for the adoption of renewable sources, although limited, the applicable tax regulation always requires careful analysis, and sometimes prevents the exploration of technological opportunities or pioneering initiatives. However, the recent normative resolution ANEEL № 687, modifying some clauses on resolution $\mathrm{n}$ - 482, introduced the important possibility of distributed photovoltaic generation, with some incentives ${ }^{[22],[23],[24]}$. The user can invest in photovoltaic plant in a region, insert the energy into the grid. The same interested user can consume this energy elsewhere, not paying the energy tariff itself, paying only taxes, network usage fees, and any consumption balances higher than those previously inserted.

Thus, the legal and regulatory framework, and recent state incentives, can allow the exploitation of systemic arrangements previously unfeasible. It is also notelike the existence of financing products released by state promoted investment banks, such as Banco Nacional de Desenvolvimento Econômico e Social (BNDES) ${ }^{[31]}$, where specific financial products tailored for the generation of clean energy from renewable sources, an important incentive for those groups that comply with the strict rules of that bank.

As there are no examples or reported cases of sugarcane mills and energy plants with ongoing APV initiatives, the entire feasibility estimative here was evaluated for a hypothetical mill, arbitrarily located in São Carlos, SP. All typical values of agronomic and industrial performance were obtained from sectoral reports, average figures and data collected on sector reviews, and from the scientific literature.

As a premise for the evaluation performed, was imposed the condition of non-reduction of the planted sugarcane plot area and keeping the same proportion on production mix sugar versus ethanol ratio, same cogeneration by burning bagasse biomass using typical plant performance, using typical sectorial figures. The APV approach was applied incrementally to the hypothetical existing sugarcane plot area. The energy from the APV setup will be integrated to that electricity generated in the thermal plant using biomass burning, allowing integrated management.

Based on the foregoing, the materials and methods used are described below.

i. For the desired plot region, the availability of solar energy, the average irradiance throughout the year, was verified. The region of São Carlos, SP was chosen. For the estimation of the available solar energy, the Reference Center for Solar and Wind Energy (Centro de Referência para Energia Solar e Eólica - brazilian portuguese) - CRESESB ${ }^{[25]}$ data covering the entire national territory were used. The result was normalized to one hectare, that is, obtaining the available solar energy in one hectare per crop harvesting season, one entire year.

ii. A hypothetical sugar-energy mill plant was configured, using the typical parameters, using the average results and figures in sugarcane yield in tons per hectare of the region (TSH) (brazilian portuguese $\mathrm{TCH}$ ), total recoverable sugar levels (TRS) (brazilian portuguese ATR) agro-industrial yields typical of the sector, all obtained from sectorial reports. Data comes from the last sectoral overview present in the Pecege ${ }^{[26]}$, for the 2019/2020 harvest season.

iii. All results were normalized to one hectare, thus allowing comparison with other mill plants, other regions, the comparison between the typical sugar-energy baseline, which was compared with the APV configurations mentioned below.

iv. To evaluate the probable effects of the APV approach on sugarcane crop, each element or item of cost, whether they result from the physiological needs of the plant, agronomics, management, and performance were estimated. A table was generated, listing each element considered.

v. To evaluate the probable effects applicable in photovoltaic generation, either due to agronomic or systemic issues, i.e., the cross-effect and symmetrical effect of the above item, a table was also made listing each probable effect and an estimate value or its applicability. 
vi. For each effect considered, its estimated magnitude of impact in cost or performance were applied in the typical results of the hypothetical sugar and energy plant.

vii. Based on the considerations of mutual influences, a proposal or design of the APV configuration has been designed optimized for the sugarcane energy case.

viii. For the hypothetical plant considered, the APV project conceived was installed incrementally in the normalized area of one hectare, the same sugarcane plot area, that is, a certain area of photovoltaic modules per hectare, following the project recommendations, without reducing the sugarcane planted area.

ix. Capital Expenditure (CAPEX) was estimated using typical figures of photovoltaic plants, based on data from sectoral reports, periodic studies published by Brazilian Photovoltaic Solar Energy Association (Associação Brasileira de Energia Solar Fotovoltaica - brazilian portuguese) - ABSOLAR ${ }^{[27]}$, and Greener ${ }^{[28]}$. The values were duly adjusted by the requirements of the APV project proposed for the sugar-energy crop and considering the cross effects, for each item of cost and photovoltaic yield, the effects caused by the combined use of land in agricultural crops were estimated.

$\mathrm{x}$. All components, systems, and equipment have been designed to support a 25year life cycle, typical for the photovoltaic sector. To cover the replacement costs of an item that fails or does not support this period, the replacement costs of these were considered over the period considered, amortized in operational expenditure (OPEX).

xi. With all the cost effects considered, and applying the estimates resulting from synergies, management adjustments, probable effects on agro-industrial yield, biomass energy generation, and photovoltaic power generation, the revenue of the new combined sugarcane-energy plant plus APV was calculated. It has always been considered the period of one crop harvest season year, per hectare.

xii. The energy price considered was the Brazilian Chamber of Electrical Energy Trade $(C C E E)^{[29]}$ know as Settlement Price of Differences (PLD) energy price, and was considered the same average value found by Pecege ${ }^{[26]}$ in the sectorial report, value without the state sales taxes.

xiii. For the opportunity cost, was applied the same rate of return of national treasury debt securities, used for the 25-year period, deflated by the National Broad Consumer Price Index (IPCA $)^{[30]}$.

xiv. Finally, cash flow was elaborated, considering the period of 25 years. Net Present Value (NPV), Internal Rate of Return (IRR) and Simple and Discounted Payback were calculated for the case of equity investment.

xv. An alternative cash flow was made using third-party capital, using a specific state sponsored financing products tailored for photovoltaic plants, BNDES FINEM Energia ${ }^{[31]}$.

xvi. The results were compared between the pure sugar-energy baseline and the combined sugar-energy plus APV approach for three coverage proportions areas.

xvii. Based on the results, a sensitivity analysis was made on the main factors influencing viability, such as currency exchange rate, energy price, equipment cost, and efficiency of solar energy collection.

xviii. In the sake of integrated performance comparison, an evaluation of energy and crop yields combined index was calculated, using APV performance indicators proposed by Willockx et al. ${ }^{[32]}$.

xix. Also, in sake of a comparative or alternative analysis, a hypothetical conventional Photo Voltaic (PV) installation, ground mounted, was conceived. In such case, conventional PV was mounted on clear ground, with the same number of PV modules employed on APV approach, but now with the crop area reduced accordingly. Conventional PV practices and rules was applied. The reduced crop area was considered to behave with the same productivity per area. Capital Expenditures and Operational Expenditures adjusted by PV common practices. 
xx. With the APV sugarcane approach performance results, and same resulting from the conventional ground mounted PV a comparison on the APV feasibility approach on sugarcane was presented.

To confirm some information, and hypotheses, agronomic effects and economic data, the author visited an important group of sugarcane mill and energy plants in the region near Araçatuba SP, about $200 \mathrm{~km}$ from São Carlos, SP. During the visit there, meetings with the technical and management teams, important information emerged, which are presented throughout here along with corresponding arguments The results of the application of the described methodology are presented below.

\section{Results and Discussion}

For the compilation of all the results obtained by the approach presented, the analyses and the corresponding cost and performance estimative required to evaluation of economic feasibility, all data were grouped in a spreadsheet. Due brevity this spreadsheet is not presented here, but the main results and discussion will be discussed along the following lines.

According to the methodology, the first step was establishing the mutual influences of the APV approach on agricultural practices and crop culture and vice versa. The first analysis was related about the effects on photovoltaic productivity and costs caused by sugarcane crop production nearby, i.e., refers to the effects caused by agricultural culture presence applicable to the installation of photovoltaic modules. 16 effects were identified. Some of them will be discussed later.

Also was performed the symmetric analysis, the impacts caused by the APV approach, on the agricultural crop productivity and practices efficiency, and refers to the probable effects that the presence of photovoltaic modules would have on agricultural crops. A total of 18 effects have been studied, and the most important effects are pointed out below.

In both analyses, any crossed and synergistic effects were listed and estimated, item by item, whether positive or negative. The effects can derive to eventual investments requirements, change on operational process or costs, gains or losses in productivity. All effects are combined resulting on adjustments on CAPEX, OPEX and cash flow.

The main question that emerged from the cross effects analysis was the necessary evaluation or confirmation whether the sugarcane crop would be tolerant to the shade and the magnitude of this influence. This item directly affects the entire architecture and economic results of the combined APV approach. This motivated a thorough search in the literature for applicable cases and results.

The sugarcane, according to Rodrigues et al. ${ }^{[19]}$ is a typical C4 plant, a class that indicates the behavior and by what means photosynthesis occurs, and in this case, an example of high efficiency in the capture of $\mathrm{CO}_{2}$ and its transformation into biomass. For this reason, this author argued that any reduction of solar irradiance could cause a decrease in biomass generation. According to Sage et al. ${ }^{[20]}$, there is the question of whether sugarcane undergoes some saturation in its absorption capacity of photosynthetic $\mathrm{CO}_{2}$ at high levels of irradiance. And in both studies, leaf temperatures above $34^{\circ} \mathrm{C}$ reduce the absorption capacity of $\mathrm{CO}_{2}$ by the photosynthetic pathway. On the responses to the irradiance levels mentioned in the texts, there are indications that in the Southeast and Midwest regions of Brazil the effects of solar irradiance present there, combined with leaf temperatures, are operating close to the sugarcane asymptotic level of $\mathrm{CO}_{2}$ absorption saturation by photosynthesis.

In Rodrigues et al. ${ }^{[19]}$, the results showed that leaf temperature above $30^{\circ} \mathrm{C}$ decays the sugar concentration, suggesting that this factor is more preponderant than the light intensity and its duration. There is energy expenditure when sweating occurs at higher temperatures. Marrou et al. ${ }^{[4],[5]}$, Marrou et al. ${ }^{[17]}$ and Hassanpour and Selker ${ }^{[33]}$ in their results obtained with plants and grasses C4, claims that even a small shade, although temporary, decreases leaf temperature, and increases local humidity, reducing the need for artificial irrigation.

Dupraz et al. ${ }^{[3]}$ showed an important correlation between APV results and agroforestry systems. Agroforestry systems are those where an agricultural crop coexists with another forest crop, in arrangements optimized for the land use, nutrients and especially sunlight. In Brazil, studies of agroforestry arrangements with sugarcane were carried out, as in the works of Schwerz ${ }^{[34]}$, Schwerz et al..[35], Schwerz et al.. ${ }^{[21]}$, Caron et al. ${ }^{[36]}$, Elli et al. ${ }^{[37]}$ and Pinto et al. ${ }^{[38]}$.

In the works described above, with emphasis on the result obtained by Schwerz ${ }^{[34]}$, and Schwerz et al. ${ }^{[21],[35]}$, agroforestry arrangements were created in Frederico Westphalen, RS, where sugarcane areas were cultivated intercropping/in combination with trees, carefully 
configured in arrangements with spacings in specific plot geometries.

Trees of the species Aleuritis fordii (tungue) were planted at distances of $12 \mathrm{~m} \times 12 \mathrm{~m}$, or 6 $m \times 6 \mathrm{~m}$, measured between sugarcane lines, and the effects on its productivity were analyzed. According to the report, using tungue, in the spacing $12 \mathrm{~m} \times 12 \mathrm{~m}$, there was a small reduction in biomass production, about $-8 \%$, but there was a significant increase in sucrose content, $+11 \%$. In the case of $6 \mathrm{~m} \times 6 \mathrm{~m}$ spacing, there was a reduction of both $-27 \%$ of biomass productivity and $-21 \%$ sucrose.

As the size of the tungue canopy, heights, diameters, and relative positions of this species are documented, it was possible to estimate which would be the equivalent sizes of photovoltaic modules that would cause the same shadow effects. By doing the average shade size calculations, it was found that the $12 \mathrm{~m} \times 12 \mathrm{~m}$ arrangement would be equivalent to a photovoltaic modules' coverage area of $1.8 \%$ of the hectare, and the coverage of $6 \mathrm{~m} \times 6 \mathrm{~m}$, equivalent to $16 \%$ of the area in the hectare.

Obviously, photovoltaic modules do not compete for nutrients and water, and therefore extrapolation of results can be considered pessimistic. This result corroborated the argumentation and data obtained by Dupraz et al. ${ }^{[3]}$.

The proposed setup for the Agro photovoltaic system applied to sugarcane crop is diagramming in Figures 1 and 2, and these configurations were the ones used for the entire cost survey, investments, and feasibility analysis.

The photovoltaic modules were placed at sufficient height to allow the most common crop management practices, and oriented so that the sun, in its trajectory throughout the day, did not produce superposition of shadows, and the paths of these were homogeneously distributed on the plot.

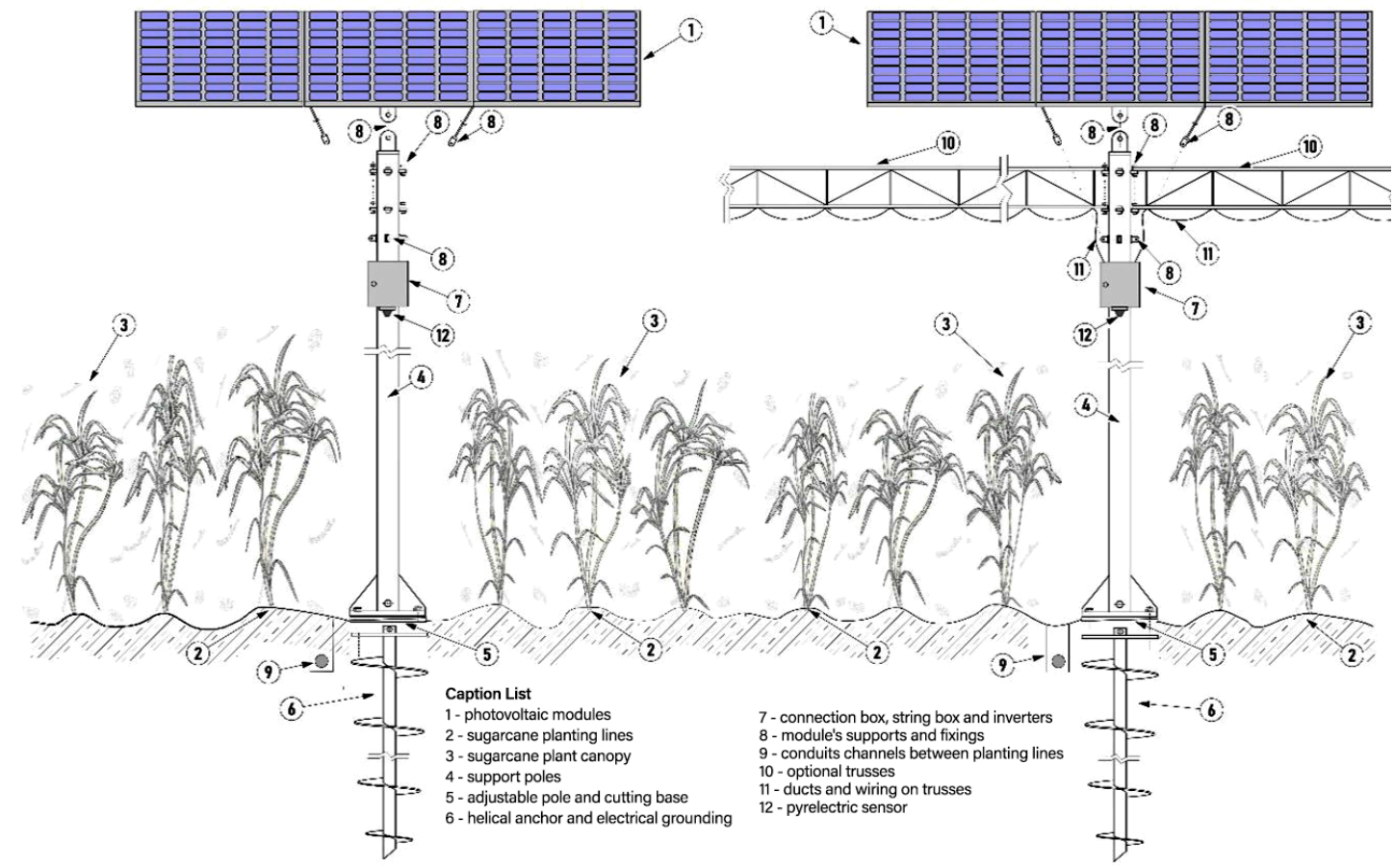

Figure 1. Conception of the APV system applied to sugarcane and energy plant Source: Original research results

Note: The photovoltaic modules are installed elevated allowing the harvester transit of transshipment wagons, trucks, motorized sprinklers. Note that the installation may contain poles isolated or connected by struts. Wiring, cabling, connection boxes and circuit breakers, as well as pyroelectric sensors follow the poles and trusses. Structural foundation by screw piles, helical anchor.

In Figure 1, photovoltaic modules are housed in poles, about $8 \mathrm{~m}$ high, clearance due to the automated harvesting equipment requirement, which created the need to install elevated and robust structures, and thus their foundations, to support a set of photovoltaic modules. The height allows the automatic harvester transit, stems lifting conveyor, the wagons, trailers for transshipments. Each pole contains a set of photovoltaic modules and are oriented so that the top faces are tilted in their normal 
north, in Brazil, by the value of the local latitude. This allows a good yield gain in the capture of solar irradiation along all day. The poles are isolated, without structural braces or links to the ground, but depending on the management practices of the sugarcane on specific site, allow the use of trusses, and the aerial cabling, at a height sufficient to not cause harvest issues.

On the other hand, APV mounted on about $8 \mathrm{~m}$ high poles, produces a very interesting behavior on photovoltaic performance. Using manufacturer's data, it presented a reduced operating temperature, increasing photoconversion efficiency. Also was noted the reduction on dust accumulation, and a very important influence of increased capture of the secondary irradiation coming from the crop canopy. It justifies the use of bifacial photovoltaic modules, and it caused a significant overall increase in efficiency, and will be discussed later.

Figure 2 shows the distribution of the modules in top view in a hypothetical plot, as well as the positioning of the poles in the spaces between rows of sugarcane lines.

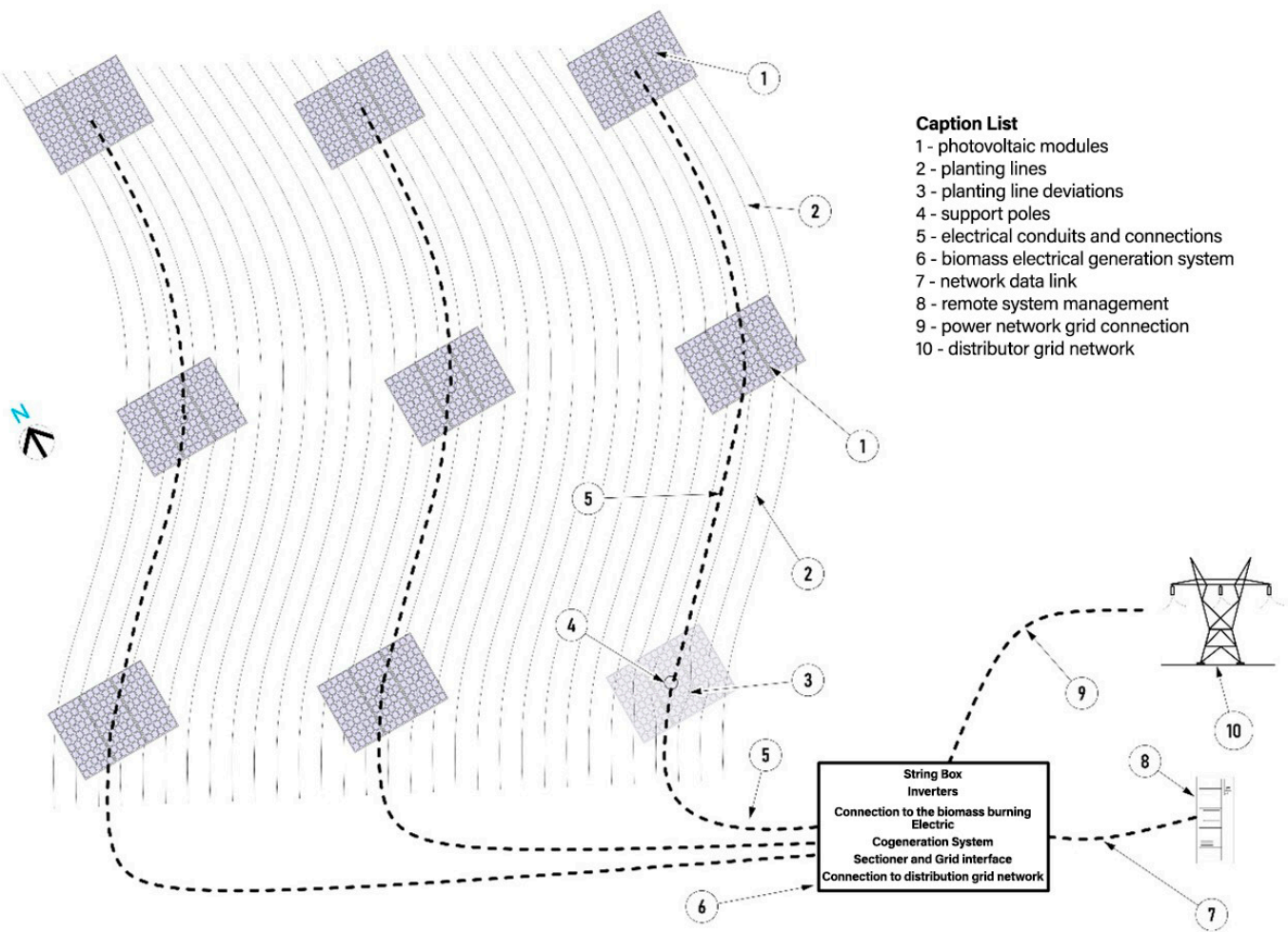

Figure 2. Conception of the APV system applied to sugarcane crop and energy mills Source: original research results

Note: The poles and cabling connections follow the sugarcane lines, and connect with the biomass cogeneration plant, taking advantage of existing infrastructure, or via distributed generation approach according to normative resolutions $n$ ㅇ 687 of $\operatorname{ANEEL}^{[23]}$.

The project fulfills one of the primary aspects, the non-reduction of the planted area and avoids any changes as possible in the process or practices of crop management. Spacing allows the passage of harvesters, wagons, sprinkler, and fertigation machines.

To allow the passage of large agricultural machines, the poles are placed in the clear spaces between the sugarcane planting lines, sometimes with small deviations. Same path allowing also underground cabling wiring harness, conduits hiding between planting lines, according to Brazilian regulatory requirements $A B N T^{[39]}$. If required, airway passage of wires from the energy generated by photovoltaic modules, light struts are installed between the poles. This possibility has been confirmed, since the harvesting machines follow lines pre-programmed by Real Time Kinematic Global Positioning System (RTK GPS). This reprogramming has a marginal cost and is done at the time of sugarcane plot preparation.

The management of pesticides and fertilizer application required some attention. Thus, inter space distance of the poles followed, for example, the careful programming of the trajectories of the sprinkler machines. The presence of photovoltaic modules prevents, for example, the use of the vinasse-based aerial sprinkler, therefore, the use of conventional machines, in paths also 
programmed by RTK GPS has been cost evaluated.

The use of airplane air dispenser pesticide application has been ruled out due to the risk of accidental impact on PV modules, although this practice is already abolished by legislation in some states due to the risk of chemical spray drift over protected areas. The use of Remote Piloted Vehicles (RPV), aerial drones proves to be feasible here. A small increase in the cost of fertilization and application of pesticides was considered in the agro-industrial costs in the combined scenarios.

According to Trommsdorff ${ }^{[11]}$, the presence of photovoltaic modules inhibits the risks of ice and frost. On the other hand, the high height modules are susceptible to winds, and the elevated structure had to consider any occurrence of wind gusts. This item influenced the budget because had increased cost of the installation, and imposed requirements on poles about the specification of withstand side winds at the required safety levels in the region. The budget of the poles in CAPEX carries this requirement.

Depending on the region, the lateral wind gust loads are high, just the case of the site of the hypothetical installation chosen for this analysis, São Carlos, SP. For this reason, the use of poles on top of metal helical anchor, screw piles, was adopted. This choice is also justified for another reason. It was detected that the use of concrete shoes could cause chemical risks to the soil, additional care in management as well as the difficulty of removal. The use of helical anchor, screw piles, is a consolidated practice in some sectors and can be installed and removed quickly and do not cause chemical damage to the soil. They also allow the electrical grounding, a normative requirement to protect the photovoltaic modules installation against atmospheric discharges.

In the analysis of the mutual effects, there was the opportunity to take advantage of the increase in soil moisture resulting from partial shade, reducing the need for artificial irrigation. Dupraz et al. ${ }^{[3]}$ showed that there was a small reduction in irrigation needs in APV and agroforestry arrangements, and, therefore, this cost item was reduced correspondingly in this simulation, in the same volume suggested in the references.

In the system synergies, effects such as insurance cost, surveillance, fences, were reduced in the combined simulation, because opportunities for reduction were observed.

In Figure 2 the project includes the connection of the energy generated by photovoltaic modules directly on the biomass burning thermal generation plant control system. In such approach taking advantage of all the existing installation, the voltage elevator and sectional substation, the formal homologation, licensing, and regulatory clearance of insertion to the network grid was already made. The use of all automation and management installation already present is a clear synergy gain. A substantial cost reduction CAPEX and OPEX occurred here. Figure 3 diagrams this systemic conception.

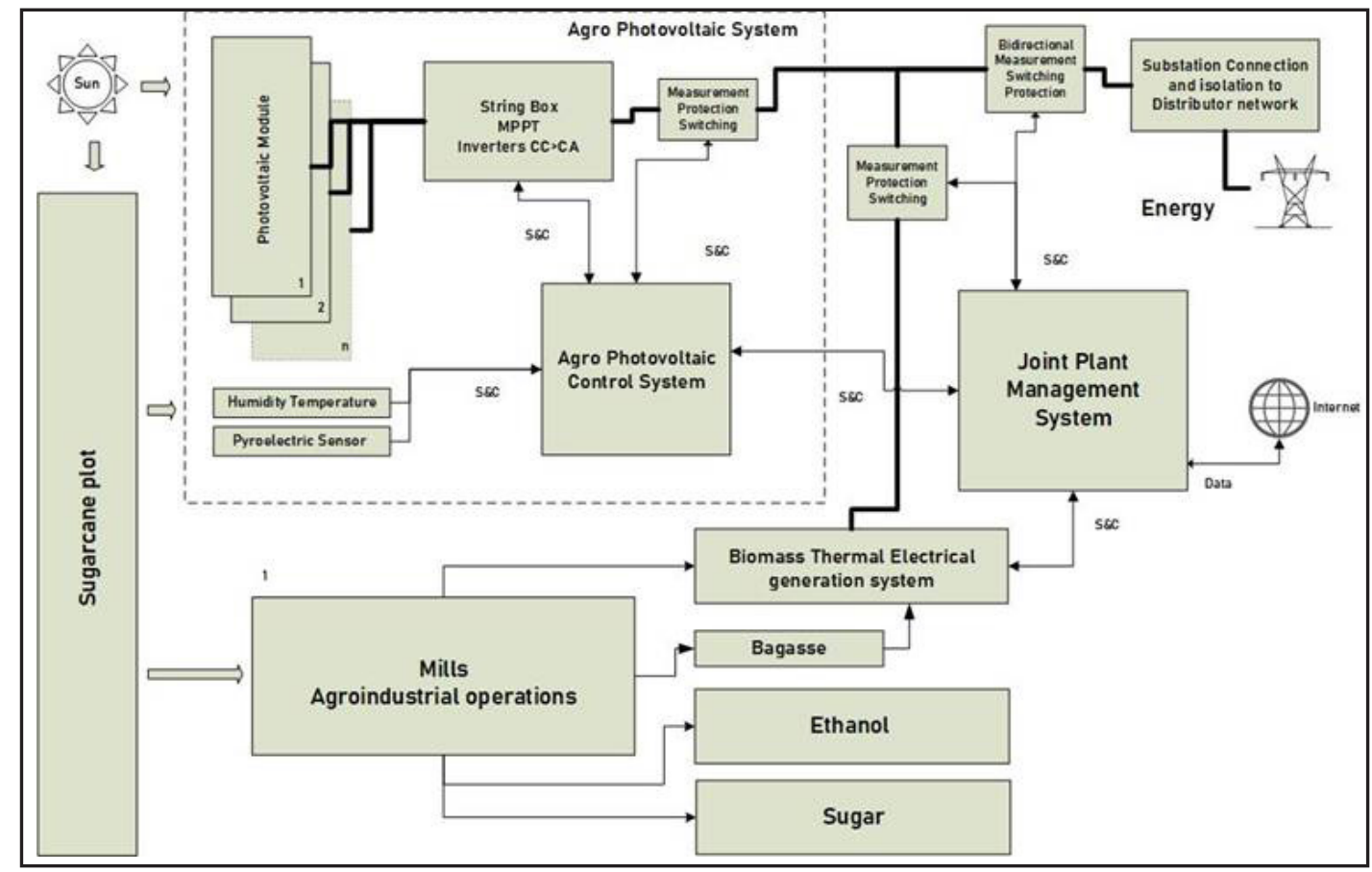

Figure 3. Systemic Overview APV Design applied to sugarcane energy plant

Source: original research results

Note: The APV system is connected to the existing biomass thermoelectric cogeneration plant system, and to the plant's central management system, sharing the same link for the distribution network. 
Figure 3 shows that the APV system integrates agro-industrial operation and electrical cogeneration by biomass, allowing centralized management. This conception brings savings in the necessary investments. It assumed that the normative and legal requirements, commissioning, and homologation of the insertion of energy in the distribution network by the existing biomass energy plant unit are already fulfilled. In this case the additional cost of documentation, inspection, commissioning of photovoltaic insertion was accounted for, but is reduced, with noticeable savings in an item of significant cost in conventional photovoltaic installations.

In Figure 3, the APV is connected before the substation and shares access to the distribution network. This is valid and economical for plots near the mill energy plant. If the APV is too far from the energy plant, the cost of cabling can grow. If the APV plot is within the harvest capture radius of the mill plant, the distributed cogeneration approach can be used, where the plot with APV directly accesses the distributor's grid network, according to the rules in resolution $N^{\circ} 482$ and $n^{\circ} 687$ of ANEEL ${ }^{[22],[23]}$. The management remains centralized in the mill plant, via the data network.

Among the synergies, it was observed that it is possible to use the Labor Force (LF) required due the additional management of the energy that was being generated by APV also being allocated to the already existing management personal of the mill plant. In short it is possible to use the same management personal in charge of mill thermal plant, as well on the industrial maintenance duties. The accumulation of service is perfectly acceptable, given the high degree of automation existing in photovoltaic systems, and the ability to integrate into the existing sugarcane energy automation and control system. This allowed for significant reduction of OPEX for the combined scenario.

Centralized management allows the exploration of optimized strategies, aimed at exploring the APV generation combined with biomass thermoelectric generation. Use of daytime APV energy, saving bagasse for night use, or for future use in harvest interseason, are one of the multiples possible scenarios.

About environmental licensing, until now there is not explicit federal regulation for this type of APV approach. However, the Brazilian National Environmental Council (Conselho Nacional do Meio Ambiente in brazilian portuguese - CONAMA) ${ }^{[40]}$. Resolution $N^{\circ} 27$ of 06/27/2001, clause 1-IV informs the requirement for Simplified Environmental Impact Report (RAS), due the photovoltaic system is now classified as low environmental impact. In the state of São Paulo, Environmental State Secretariat (Secretaria de Infraestrutura e Meio Ambiente in brazilian portuguese) Resolution (SMA) ${ }^{[41]} n^{\circ} 74 / 2017$ relates the licensing requirements according to the installed powers and requires formal authorization if there is planned a suppression of native vegetation or use of water sources areas. As it is assumed that the environmental licensing for the sugar-energy operation is already regularized, the estimated costs for APV environmental licensing in the same land is presented as a small additional cost. In the CAPEX estimative, administrative cost of project implementation, this factor was included, increasing the typical value by $10 \%$, a pessimistic hypothesis ${ }^{[28]}$.

About the lease of the land, an important aspect was detected. In $30 \%$ of cases, sugarcane plantations are performed on leased land ${ }^{[26]}$. In the lease agreements are explicit clauses on the use of the site for sugarcane culture, by certain number of harvest seasons. The use of the same land for APV and sugarcane, simultaneous and combined, can lead to discussion about contractual amendments, eventual extensions of rental time, and this possibility was not considered in the cost assessment performed here. Competition with other crop cultures also suggests the possibility or risk of lease cancellation.

Therefore, there are possibility to remove the modules and structures in shorter time. It is initially suggested that the APV approach should be installed only on land where there is long-term contractual predictability, or on the mill plant's own premises land.

The risk of fire in sugarcane crops was always pointed and eventually an opportunity to exercise possible extremely positive synergy. It is possible to use pyroelectric sensors connected in photovoltaic modules, taking advantage of the inverters' own data network, data link connected directly to management control center. In case a fire occurrence or even an increase in temperature, there will be an alarm, and the possibility of rapid mobilization of the fire brigade to combat it. In Figures 1 and 2, pyroelectric sensor installations were planned. In Figure 3, sensors connect directly to the centralized data and management system, and these infrastructures were included in the CAPEX cost assessment.

As in every photovoltaic installation, the high CAPEX cost primarily comes from the components, mostly imported. Thus, the use of sectoral data ABSOLAR ${ }^{[27]}$ and Greener ${ }^{[28]}$ carries the currency 
exchange ratio occurred in recent years. Quotations were also made by the author. It was noted that the budgets obtained were about $20 \%$ above the typical sectorial values. In a quick analysis, it was observed that large photovoltaic enterprises make use of scale savings, directly importing the photovoltaic modules and inverters of partners or their headquarters abroad, and enjoying tax incentives in some states ${ }^{[28]}$.

Among the equipment that had increased cost due high currency exchange ratio circumstances are photovoltaic modules, mostly imported, although national production has recently begun. These items have a predicted lifetime between 25 and 30 years, from which the system lifetime and cash flow horizon was also established. The operational life was established in 25 years, typical of the sector, which is the value considered in the calculation of NPV and cash flow expectative.

As pointed before, bifacial silicon photovoltaic modules were used, that is, they can generate energy both by the upper face, pointed at the sun, and from the lower face, pointed to the canopy of the sugarcane in the soil. It is an important innovation and promoter of higher return because the sugarcane canopy presents significant diffuse omnidirectional reflectance, mainly on the Near Infra Red (NIR) spectral region, just near that of maximum silicon photon response. This phenomenon allows substantial light energy to be collected not only from the scattering coming from sugarcane just below the photovoltaic set, but also by those outside the influence of direct shadow. In the performance of photovoltaic modules, the calculation of the response of the bifacial arrangement was applied, following orientation contained in the manufacturer's catalogue. For the calculation, the value of albedo 0.2 typical of sugarcane was used. Considered also an increase efficiency by reduced operating temperature due the height above ground. Also was considered in the yield of photovoltaic conversion, an annual decrease due to aging. Light Induced Damage (LID) and Proton Induced Damage (PID) was applied using manufacturer's data. In the first year a combined decrease of $2 \%$ followed by $0.5 \%$ per year, both considered in the calculations of income of electricity generation in the cash flow prediction.

Another significant cost factor is that of the inverter. This equipment, also called the Power Converter Unit, transforms the photo generated voltage originally in Direct Current (DC) format into voltage on Alternating Current $(A C)$ format useful to be injected into the distribution network. The inverter is the most expensive and critical item of the photovoltaic system. This is complex equipment due normative compliance with the strict safety standards of ANEEL ${ }^{[39]}$. Despite having a warranty term ranging from 5 to 8 years, this component usually fails in $30 \%$ of cases over a period of 10 years $^{[28]}$. Good industry practice recommends the provisioning for replacement of at least one set over the projected lifetime of the system ${ }^{[27]}$. OPEX budgets included provision for the exchange of an inverter over the estimated 25-year life cycle, and the provision to exchange all other components, such as circuit breakers, connectors, keys, at least once in the lifetime predicted for the photovoltaic system.

In the evaluation of operational costs, some cost reductions were applied, exploring synergies. Systemic advantages were found, which allowed reasonable cost reduction in several items. The administrative costs of photovoltaic installation have been reduced because it is assumed that the existing automatism, mill control system as well as the current administration of the sugar-energy mill and cogeneration by burning biomass, will deal with the APV system management, mostly fully automated.

However, there was an increase in installation costs due to the need to keep the sugarcane crop management as close as possible to the original practices. The costs of the photovoltaic poles, to be installed at $8 \mathrm{~m}$ height, and their helical anchor were estimated and quoted in conventional manufacturers of photovoltaic structures. Budgets were obtained abroad, and the costs here included import taxes. This factor alone caused substantial increase in CAPEX. It was clear that is required an engineering effort to reduce costs and obtain industrial scales in these specialized structures, a cost induced development cycle as has been happening in other countries, especially in Italy, China and Germany ${ }^{[15]}$. Another factor was the increase in the cost of wiring, cabling, since the modules and poles are scattered throughout the plot field, and the need to use standardized conduits according to Brazilian Association of Technical Standards (Associação Brasileira de Normas Técnicas in brazilian portuguese - ABNT) ${ }^{[39]}$.

The evaluation begins by calculating what would be the photovoltaic energy generated for the case where a certain percentage of photovoltaic modules were installed on a typical sugarcane crop plot. Using CRESESB ${ }^{[25]}$ data obtained for irradiance at the plot site, municipality of São Carlos, the complete calculation was possible and was performed for the case described here.

Finally, it was possible to contemplate the effects and results of everything that was exposed, 
as shown in Table 1. Estimates of crop management corrections, irrigation, harvests practices and performance, and possible changes in operating costs were applied in CAPEX and OPEX, as discussed earlier. As a premise, there was no reduction in the sugarcane plot area.

In this table are presented three choices of sugarcane crop area covered by photovoltaic modules. The first covered area value, with the initial intention of being very conservative, was to allow the effects of shading on sugarcane to be minimal and well distributed, so that keep marginal any reduction in the of biomass photosynthetic production.

Thus, in the first scenario, the coverage by photovoltaic modules around $1.3 \%$ of the hectare of sugarcane was adopted. Table 1 details the costs for this architecture. In one hectare, 60 photovoltaic bifacial modules of $400 \mathrm{Wp}$ each will be distributed, totaling an installation with a nominal power of $24 \mathrm{Kwp}$ per hectare. This choice corresponds to a typical industrial implementation capacity, with several cases and suppliers. This allowed the collection of typical budgets and economical return comparison. For this size, in conventional PV approach, with modules near the ground, and using typical parameters of energy cost in the regulated captive market in the state of São Paulo, the typical sector figures indicate a payback of 7.6 years. In the state of Minas Gerais, due to a series of tax incentives, payback would be around 4.6 years ${ }^{[28,}[27]$.

The 60 photovoltaic modules were grouped into 10 elevated poles, with 6 modules each. Between the poles were wires and cabling by ABNT style conduits, located underground in buried channels following the crop inter lines. The cost of this plot preparation was included in the CAPEX of the described installation.

In each set of photovoltaic modules are installed the other required equipment, such as stringbox, circuit breakers, wires and conduits, the inverter, following connection with the internal electrical network of the mill plant intended for biomass thermal electricity generation, that is, before the voltage elevation station, measurement and switching circuits breakers, in the station intended for insertion on the medium voltage distribution grid network of the region.

Table 1 shows the CAPEX required for this coverage, energy production, overall figures for the APV configuration described. 
Table 1. Summary of the overall results comparing the conventional sugar-energy baseline and the APV scenarios

\begin{tabular}{|c|c|c|c|c|c|c|c|}
\hline \multirow[b]{2}{*}{ Results } & \multirow[b]{2}{*}{ Unit } & \multirow{2}{*}{$\begin{array}{l}\text { Baseline } \\
\text { sugarcane-energy }\end{array}$} & \multicolumn{3}{|c|}{ APV approach } & \multicolumn{2}{|c|}{ Conventional PV } \\
\hline & & & $\begin{array}{l}\text { APV coverage } \\
1.3 \%\end{array}$ & $\begin{array}{l}\text { APV coverage } \\
1.8 \%\end{array}$ & $\begin{array}{l}\text { APV coverage } \\
16 \%\end{array}$ & $\begin{array}{l}\text { PV coverage } \\
1.8 \%\end{array}$ & $\begin{array}{l}\text { PV coverage } \\
16 \%\end{array}$ \\
\hline \multicolumn{8}{|c|}{ Agronomical Aspects } \\
\hline Total Recoverable Sugar Levels (TRS) & $\mathrm{Kg} \mathrm{t}^{-1}$ & 134.75 & 134.75 & 150.78 & 103.93 & 134.75 & 134.75 \\
\hline TRS ha-1 & $\mathrm{Kg} \mathrm{ha}^{-1}$ & $10,302.99$ & $10,302.99$ & $10,595.94$ & $5,878.18$ & $9,823.92$ & $5,947.84$ \\
\hline Productivity Sugarcane Yield Index (TSH) & Tc ha-1 & 76.46 & 76.46 & 70.28 & 56.56 & 72.90 & 44.14 \\
\hline Agro-industrial revenue per harvest season (hs) & $\mathrm{R} \$ \mathrm{ha}^{-1} \mathrm{hs}^{-1}$ & $11,124.17$ & $11,124.17$ & $11,440.46$ & $6,346.69$ & $10,606.92$ & $6,421.90$ \\
\hline $\begin{array}{l}\text { Productivity biomass electrical energy per } \\
\text { harverst season (hs) }\end{array}$ & Kwh ha ${ }^{-1} \mathrm{hs}^{-1}$ & $5,180.17$ & $5,180.17$ & $5,180.17$ & $5,180.17$ & $5,180.17$ & $5,180.17$ \\
\hline Biomass electrical energy internal mill self-use & Kwh ha ${ }^{-1} \mathrm{hs}^{-1}$ & $1,991.78$ & $1,991.78$ & $1,991.78$ & $1,991.78$ & $1,991.78$ & $1,991.78$ \\
\hline Biomass electrical energy for sale & Kwh ha ${ }^{-1} \mathrm{hs}^{-1}$ & $3,188.38$ & $3,188.38$ & $3,188.38$ & $3,188.38$ & $3,188.38$ & $3,188.38$ \\
\hline $\begin{array}{l}\text { Biomass electrical energy sale revenue per } \\
\text { harvest season per hectare }\end{array}$ & $\mathrm{R} \$ \mathrm{ha}^{-1} \mathrm{hs}^{-1}$ & 879.29 & 879.29 & 879.29 & 879.29 & 879.29 & 879.29 \\
\hline \multicolumn{8}{|c|}{ Agro Photovoltaic Aspects } \\
\hline Number of photovoltaic modules per hectare & $\mathrm{n}$ & 0 & 60 & 88 & 800 & 88 & 800 \\
\hline Nominal Electrical energy per hectare & Kwp ha-1 & 0 & 24.00 & 35.20 & 320.00 & 35.20 & 320.00 \\
\hline $\begin{array}{l}\text { APV Electrical energy yield per season per } \\
\text { hectare per harvest season (hs) }\end{array}$ & Kwh ha ${ }^{-1} \mathrm{hs}^{-1}$ & 0 & $46,100.11$ & $67,613.50$ & $614,668.16$ & $58,830.43$ & $534,822.12$ \\
\hline APV CAPEX & $\mathrm{R} \$ \mathrm{ha}^{-1}$ & 0 & $125,102.35$ & $171,529.76$ & $1,426,214.92$ & $136,576.00$ & $1,139,200.00$ \\
\hline APV revenue per hectare per harvest season & $\mathrm{R} \$ \mathrm{ha}^{-1} \mathrm{hs}^{-1}$ & 0 & $12,709.34$ & $18,640.37$ & $169,457.87$ & $16,218.96$ & $147,445.11$ \\
\hline Total Energy yield APV Biomass & Kwh ha ${ }^{-1}$ hs $^{-1}$ & $5,180.17$ & $17,889.50$ & $23,820.53$ & $174,638.03$ & $21,399.13$ & $152,625.27$ \\
\hline \multicolumn{8}{|c|}{ Economic results APV plus agro-industrial } \\
\hline $\begin{array}{l}\text { Total combined revenue per harvest season } \\
\text { per hectare }\end{array}$ & $\mathrm{R} \$ \mathrm{ha}^{-1} \mathrm{hs}^{-1}$ & $12,089.86$ & $24,799.20$ & $31,046.52$ & $176,770.24$ & $27,791.57$ & $154,832.70$ \\
\hline Economic margin & $\%$ & 10.4 & 27.5 & 33.5 & 45.8 & 29.5 & 43.6 \\
\hline
\end{tabular}


Tabela 1. Summary of the overall results comparing the conventional sugar-energy baseline and the APV scenarios

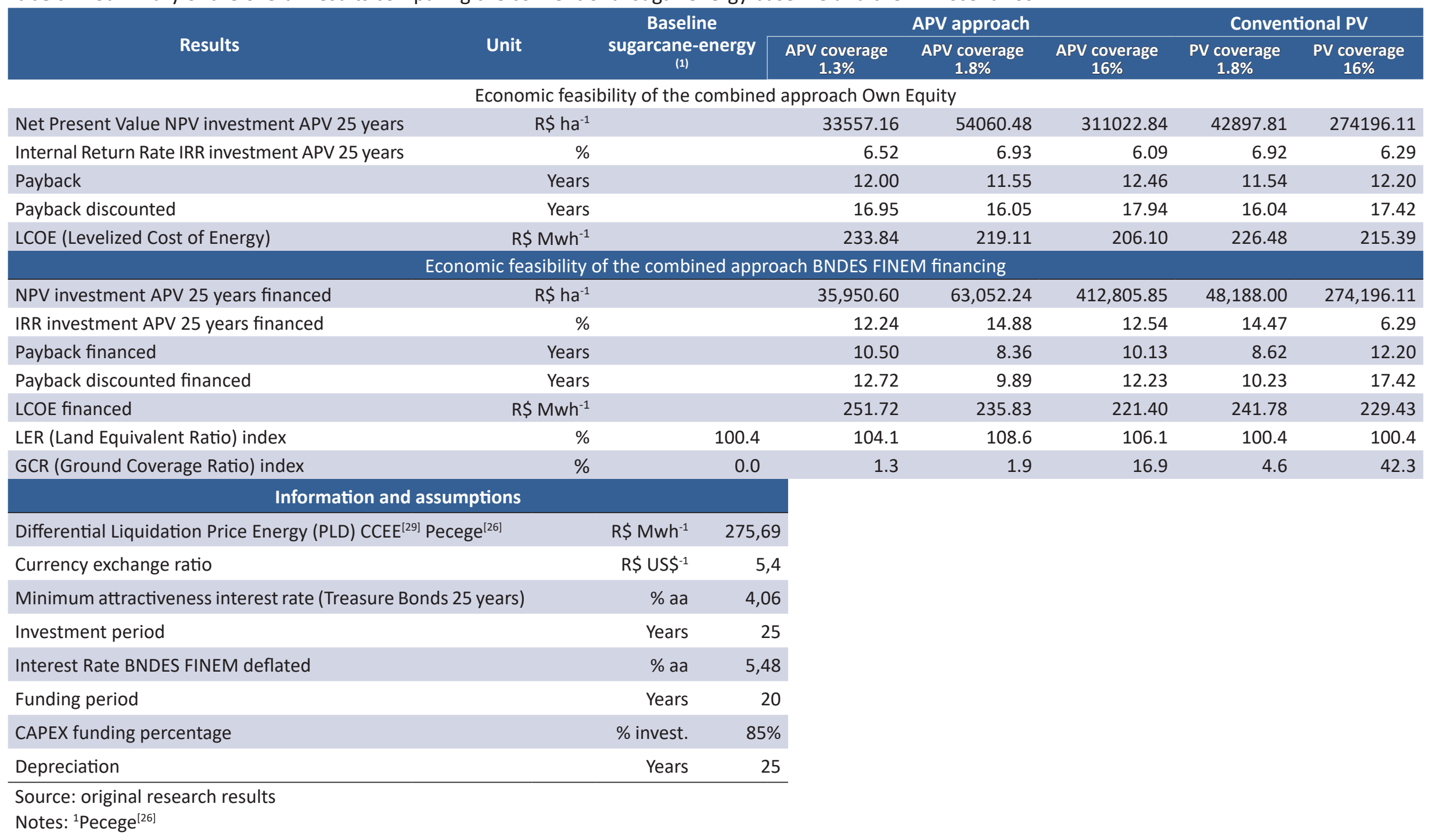


For the revenue obtained from the sale of electricity generated by biomass, data from sectorial report Pecege ${ }^{[26]}$ were used, a typical scenario of the sugar-energy sector in the 2019/2020 harvest season. Thus, the energy price, called differential liquidation price (PLD ${ }^{[29]}$ in the electricity free market, was the same value used in the sale of energy by biomass was considered also for APV, and was set on $\mathrm{R} \$ 275.69 \mathrm{MWh}^{-1}$. The connection in the outbound distribution grid network of the mill energy plant will be the same. This value was considered as free of sales taxes, according to the approach published in the Pecege ${ }^{[26]}$. State sales tax should be applied on end customer price, thus is not considered here on the feasibility evaluation.

Table 1 presents the investment costs and operating costs for the APV installation in the designed approach. In CAPEX, typical costs were shown according to sector report indices ${ }^{[28]}$. In the operational costs, OPEX, synergies were computed, aiming to establish the new cost assessment, also according to the analyses performed previously.

Table 1 also presents other considered APV coverage area that can be chosen, seeking to use the similar effects found on agroforestry experiences. The scenarios were simulated where photovoltaic coverage was around $1.8 \%$ and $16 \%$. Table 1 presents the results obtained for these larger area coverages.

The $1.8 \%$ cover simulates the shading of the $12 \mathrm{~m} \times 12 \mathrm{~m}$ arrangement of the agroforestry experiment with sugarcane and tungue carried out by Schwerz et al. ${ }^{[35]} .88$ modules per hectare are installed. This arrangement has great convenience in sugarcane management, and presents an improvement in TRS sucrose levels, about $11 \%$, despite a small reduction in TSH, about $-8 \%$ in biomass productivity. That means a more valuable harvest. When applying the corrections in agro-industrial performance, and combined with the productivity of the APV generation, this configuration proved to be the most interesting, as presented below. CAPEX and OPEX values for this coverage were extracted and adjusted from typical budgets for PV plants of the same size, adjusted accordingly ${ }^{[28]}$.

The $16 \%$ coverage simulates the shading of the agroforestry arrangement of $6 \mathrm{~m} \times 6 \mathrm{~m}$, also using data from Schwerz et al. ${ }^{[35]}$. In this case, 800 modules per hectare, allowing a large photovoltaic generation, with installed capacity of $320 \mathrm{Kwp}$ per hectare. However, the effects of the reduction of photosynthetic capacity manifest themselves, demonstrating a significant reduction in simultaneous agro-industrial production.

The vision about the APV strategy, considering the impact of the principal premise of nonreduction of crop area, imposes a series of consequences. That had raised questions about the feasibility of conventional PV approach in certain cases. As in the sugarcane energy sector one of the main APV synergy found was the fact of using the same infrastructure of biomass thermo electricity, the question arises. Which would be the results if considering the conventional PV approach instead APV? In such case, it is necessary to put all modules on ground, reducing the crop planted area. For the sake of comparison, here was performed this evaluation, using conventional PV strategies, for the same covered area and same number of photovoltaic modules per hectare employed by APV strategies.

In an interesting result, Table I also show the conventional PV approach, for the same coverage of $1.8 \%$ and $16 \%$. In such cases, the CAPEX was adjusted to ground mounted modules, using Grenner ${ }^{[28]}$ sectorial average values, and the OPEX adjusted to conventional PV practices. Structural cost decreased substantially, due reduced height, and also cabling and harness cost. Meanwhile some other OPEX cost like mowing and increased periodical dust cleaning returned.

When installing modules on conventional way, $1 \mathrm{~m}$ above clear ground, the bifacial photovoltaic modules showed a reduced efficiency when compared with the APV approach. This occurred due reduced secondary illumination coming from the self-shadowed ground. Also, in simulations was showed a reduced efficiency due increased operating temperature. PV modules at $1 \mathrm{~m}$, operates in higher temperature when compared with APV located at $8 \mathrm{~m}$ high. Using simulated data coming from panel manufacturer, PV mounted at $1 \mathrm{~m}$ operates in higher temperatures, significantly reducing the overall efficiency, mainly in tropical areas.

Another important point raised in the conventional PV approach was the reduction on the crop area. Due the PV requirements to avoid crossed shadows, as well the clearance for ground installation and maintenance duties, $1,8 \%$ of useful photovoltaic panels area means $4.5 \%$ of crop reduction area. That resulted on a reduced income by agro-industrial, reduced land use efficiency.

Using the comparison land use indices proposed by Schindele et al. ${ }^{[9]}$ and Willockx et al. ${ }^{[32]}$, the Land Equivalent Ratio (LER) where adjusted to the APV approach. In this index, a ratio of economic 
revenue of the APV approach against with the normal, sole agricultural land use, is summed with the ratio of electrical yield of the APV approach, against the potential sole photo electrical yield. The total summed value result in an index, if higher than unity, means that the combined land use had increased efficiency.

Another index proposed by Schindele et al. ${ }^{[9]}$ and Willockx et al. ${ }^{[32]}$, was the Ground Coverage Ratio (GCR), where is the ratio of the required area of photovoltaic modules to operate, against the agricultural land area considered on the combined approach.

Table 1 shows the consolidated results of the combined generation. The results of the purely sugar-energy baseline were compared, according to Pecege ${ }^{[26]}$, with the arrangement combined with APV, results calculated here for the coverage of $1.3 \%, 1.8 \%$ and $16 \%$. Also, results for conventional PV approach, using $1.8 \%$ and $16 \%$ in area covered by modules, on conventional way, mounted on ground, reducing crop area as necessary.

The federal taxes on results were calculated by net profit, according Corporate Income Tax (brazilian portugues Imposto de Renda Pessoa Jurídica - IRPJ) and Social Contribution on Net Profits (brazilian portuguese Contribuição Social sobre o Lucro Líquido - CSLL) Brazilian regulation, whit limited compensation for accumulated loss, according to the legal rules. Depreciation was established in 25 years, typical term and estimated life of photovoltaic modules, a conservative consideration, pro-tax authority. For the opportunity cost, zero risk investment, was selected the interest rate of the National Treasury Securities, redemption in year 2045, 4.08\% per year plus nominal inflation index IPCA. Its application here was deflated, without the Brazilian IPCA component index, since all cash flow was calculated without the effects of inflation ${ }^{[30]}$.

The total revenue in the average conventional sole sugar-energy baseline was $\mathrm{R} \$ 12,089.86 \mathrm{ha}^{-1}$, with an economic margin of $10.4 \%$, according to the Pecege ${ }^{[26]}$ report.

In the APV approach with photovoltaic coverage $1.3 \%$ case, the total estimated revenue was $\mathrm{R} \$ 24,799.20 \mathrm{ha}^{-1}$, obtaining an economic margin of $27.5 \%$.

In the APV coverage $1.8 \%$ the total estimated revenue was $R \$ 31,046.52$ ha $^{-1,}$ obtaining a combined economic margin of $33.5 \%$. Note that there was an increase in agro-industrial revenue, starting from $R \$ 11,124.17$ ha $^{-1}$ to $R \$ 11,440.46$ ha $^{-1}$ due to the improvement in TRS, even with a small reduction in TSH. Higher TRS means a more profitable harvest.

In the APV $16 \%$ coverage case, the total estimated revenue was $\mathrm{R} \$ 176,770.24 \mathrm{ha}^{-1}$, obtaining a combined economic margin of $45.8 \%$. Note that there was a significant reduction in agro-industrial revenue, starting from $R \$ 11,124.17 \mathrm{ha}^{-1}$ down to $R \$ 6,346.69 \mathrm{ha}^{-1}$ due to the reduction of TRS, in addition to the large reduction of TSH, both due to the lower photosynthetic irradiation available. It should be noted that this result, as well as the previous one, are conservative and pessimistic, derived from extrapolations of results obtained in agroforestry systems.

For the proposed comparison with conventional PV approach, coverage $1.8 \%$ the total estimated revenue was $\mathrm{R} \$ 27,791.57 \mathrm{ha}^{-1}$, obtaining a combined economic margin of $29.5 \%$. Note that there was a decrease in agro-industrial revenue, starting from $\mathrm{R} \$ 11,124.17 \mathrm{ha}^{-1}$ down to $\mathrm{R} \$ 10,606.92 \mathrm{ha}^{-1}$ due to the reduction of crop area and thus the reduction on harvest, even with same relative TRS.

The same behavior occurs in the in the conventional PV $16 \%$ coverage case, the total estimated revenue was $\mathrm{R} \$ 152,626.27 \mathrm{ha}^{-1}$, obtaining a combined economic margin of $43.6 \%$. Note that there was a significant reduction in agro-industrial revenue, starting from $R \$ 11,124.17$ ha ${ }^{-1}$ down to $\mathrm{R} \$ 6,421.90 \mathrm{ha}^{-1}$.

In the three APV scenarios above, and comparing with two conventional PV approach, it is evident that the APV strategies applied to the sugar-energy sector combines a substantial increase on energy income, with some improved agro-industrial results, and reinforces this as an energy producer, even with coverage of only $1.8 \%$ of its area. The resulting energy revenue APV was in the same order of magnitude as that agro-industrial, allowing the management seeking for the best price PLD in free market strategies.

Economic feasibility analyses were made, both for the case of own equity capital investment and for the financing case, using state sponsored funding products.

Analyzing the results of cash flows, summarized in Table 1, it is verified that the NPV for the estimated system life cycle at 25 years, always presented positive results in the three APV coverage scenarios, either using own capital, or funded by specific lines, both using the sector's average PLD in the $2019 / 2020$ harvest season.

For own equity, the coverage of $1.3 \%$ of the NPV was R\$33,557.16 ha-1, the IRR was $6.52 \%$. The simple Payback was 12.00 years and the Payback discounted with the opportunity cost was 16.95 years. 
For the coverage of $1.8 \%$ the NPV was $\mathrm{R} \$ 54,060.48 \mathrm{ha}^{-1}$, the IRR was $6.93 \%$. The simple Payback was 11.55 years and the Payback discounted with the opportunity cost was 16.05 years. In this scenario, a general increase in the efficiency of the combined strategy was found, highlighted as the first option scenario to be implemented experimentally, self-equity case. Note the LER index of $108.6 \%$ meaning the highest land use efficiency.

For the coverage of $16 \%$, the NPV was $\mathrm{R} \$ 311,022.84 \mathrm{ha}^{-1}$, the IRR was $6.09 \%$. The simple Payback was 12.46 years and the Payback discounted with the opportunity cost was 17.94 years. Despite the great economic yield, there is a reduction in agricultural efficiency here. Nevertheless, LER index obtained was $106.1 \%$ meaning the overall land use was increased.

Comparing with conventional PV approach, the coverage of $1.8 \%$ the NPV was R\$ $42,897.81$ $\mathrm{ha}^{-1}$, the IRR was $6.92 \%$. The simple Payback was 11.54 years and the Payback discounted with the opportunity cost was 16.04 years. Note that in this scenario, the lower CAPEX had compensated the reduced land use efficiency, reduced crop harvest area, and the reduced photovoltaic efficiency remaining in the same figure of the APV approach. The lower LER index, $100.4 \%$ points this reduced land efficiency, same as the baseline of sole sugarcane land use.

For the conventional PV coverage of $16 \%$, the NPV was R\$274,196.11 ha ${ }^{-1}$, the IRR was $6.29 \%$. The Payback was 12.20 years and the Payback discounted with the opportunity cost was 17.42 years. This result, lower LER index, $100.4 \%$ raises the concerns pointed by Dias et al. ${ }^{[10]}$, food versus energy decision that the APV strategies try to avoid.

To explore some of the state sponsored funding products, an incentive to renewable sources, a hypothetical case was calculated using the BNDES ${ }^{[31]}$ FINEM Energy Funding line. This is an institutional line with lower interest rates, promoting the implementation of renewable energies ${ }^{[31]}$. Using the published product rules ${ }^{[31]}$, the program's interest rate was calculated at $5.48 \%$ per year, the resulting rate deflated, without the IPCA component, and the 20-year financing period was used, without grace. This line allows the possibility of full financing of the investment, but it depends on the analysis of the borrower's credit profile. The usual percentage of $85 \%$ of CAPEX was simulated in all scenarios. It is important to point out that BNDES has very strict rules about eligibility of submission, in addition to those reflected in the credit risk factor, being included in the forecast of the above rate a risk considered medium.

Using BNDES FINEN as explained, for the APV coverage of $1.3 \%$ the NPV was $\mathrm{R} \$ 35,950.60$ $\mathrm{ha}^{-1}$, the IRR was $12.24 \%$. The simple Payback was 10.5 years and the Payback discounted by the opportunity cost was 12.72 years.

For the financed APV coverage of $1.8 \%$ the NPV was R\$ $63,052.24 \mathrm{ha}^{-1}$, the IRR was $14.88 \%$. The simple Payback was 8.36 years and the Payback discounted by the opportunity cost was 9.89 years. As before, this scenario showed an overall increase in the efficiency of the combined activities and allowed the financing cost to be fully paid for positive cash flow. To obtain this result, the importance of using high-performance bifacial photovoltaic modules is emphasized. This configuration proved to be the first scenario option to be implemented experimentally, proving to be self-financeable.

For the financed case APV coverage of $16 \%$, the NPV was R\$ $412,805.85 \mathrm{ha}^{-1}$, the IRR was $12.54 \%$. The single Payback was 10.13 years, and the discounted payback was 12.23 years. Even with the great economic income, even with a reduction in agronomic efficiency, is still an interesting option for those who have good record of obtaining financing.

Comparing with the conventional PV alternative, coverage of $1.8 \%$ the NPV was R\$ $48,188.00$ $\mathrm{ha}^{-1}$, the IRR was $14.47 \%$. The simple Payback was 8.62 years and the Payback discounted by the opportunity cost was 10.23 years. For the financed case conventional PV coverage of $16 \%$, the NPV was R\$ 274,196.11 ha he $^{-1}$, the IRR was $12.20 \%$. The single Payback was 12.20 years, and the discounted payback was 17.42 years. In both cases the conventional PV approach here resulted in lower efficiency compared with APV due the reduced agro-industrial income as well the reduced photovoltaic production, a long-term penalty.

All these factors allow us to highlight what are those parameters that should be monitored to evaluate the decision of APV implementation in the sugar-energy sector. In a sensitivity analysis, the following items were found as critical feasibility flags and decision check points.

- Energy Price, as per CCEE ${ }^{[29]}$ PLD rules, the commercialization price of electricity, considered here without sales taxes. In cash flow, a PLD price of 275.69 R\$ MWh-1, average for 2019/2020 harvest season was used according to that reported by Pecege ${ }^{[27]}$. For the present study, the NPV for the equity case approaches zero when the PLD goes around $\sim 215.00 \mathrm{MWh}^{-1}$. The NPV for the funded case approaches zero in 25 years when the PLD goes around $\sim R \$ 229.00$ 
$\mathrm{MWh}^{-1}$. Thus, the combined APV approach will only be feasible if the PLD remains above those levels. In 2020, during the COVID 19 pandemic, the PLD varied widely, and at the beginning of 2021 , the date of the present study, it was around $\mathrm{R} \$ 170.85 \mathrm{MWh}^{-1}$. (update: The 2021 year average PLD was $\mathrm{R} \$ 282,48 \mathrm{MWh}^{-1}$ ). In the previous 3 years, the average PLD was $\mathrm{R} \$ 230.97$ $\mathrm{MWh}^{-1}{ }^{[29]}$, slightly above the lower feasibility limit. Another way to look at this factor is to evaluate the Levelized Cost of Electricity (LCOE), a common index on the renewable energy sector, used to compare different approaches. Using the methodology pointed by Schindele et al. ${ }^{[9]}$ and Trommsdorf ${ }^{[11]}$, in Table 1 present the LCOE for all those different APV scenarios pointed above. The LCOE range from $\sim R \$ 206.00 \mathrm{MWh}^{-1}$ up to $\sim \mathrm{R} \$ 251.00 \mathrm{MWh}^{-1}$, suggesting a higher minimum PLD.

- CAPEX of the Agro photovoltaic plant. The main cost items of the installation are the photovoltaic modules, the inverter, and mainly the high height pole, designed according to the crop management requirements of the sugarcane, and the most extensive wiring harness. The first two have cost in US\$ dollars being reduced over the years, following the typical improvement curve in the semiconductor sector. A typical photovoltaic installation, medium-sized, according to Greener ${ }^{[28]}$ has an average cost of $\mathrm{R} \$ 3.88$ per Wp. In the hypothetical installation presented here, $1.8 \%$ coverage case, the cost was $\mathrm{R} \$ 4.87$ per $\mathrm{Wp}$, showing that there is a path to be explored for cost reduction via technological development. The main item causing this additional cost was the higher poles to support in $8 \mathrm{~m}$ height and its installation, wiring conduits between planting lines. Here is suggested an engineering effort to reduce this difference. It should be noted that the reduction of OPEX due to the synergies found, such as the reductions in administrative costs, simultaneous use of land, maintenance and management of the combined cogeneration, all substantial savings, were in the same order of the cost of the additional investment of the higher poles and their installation, showing the importance of the improvement of this item for the agro photovoltaic feasibility in the sugarcane energy sector.

- Currency Exchange ratio. The most critical equipment is imported, and the exchange ratio factor has severely affected the cost in recent years. A US\$ dollar around $\mathrm{R} \$ 6.00$ brings down the VPL by 33\%, and the discounted Payback goes to 22 years for the case of minimum coverage $1.3 \%$ and self-equity. One dollar to $R \$ 4.6$ reduces the payback to 10 years, showing the importance of this item.

- Efficiency of photovoltaic modules and system. Bifacial modules were efficiently found here around $21.37 \%$ in all APV scenarios here, which allowed good performance, due using secondary irradiation from omnidirectional scattering from the sugarcane canopy, and the reduced operating temperature. If the efficiency of the modules was $18 \%$, a typical value of the simple face modules, the Payback for the most favorable case goes to 14 years. This item shows the need for careful design taking advantage of all synergies and consequences of the fact that sugarcane crops are below the photovoltaic module, and careful maintenance of operating conditions. That is clear in the simulations when using the conventional PV approach, ground mounted. Using the same bifacial photovoltaic module, $1 \mathrm{~m}$ above ground, the higher operating temperature, the lower secondary irradiation, reduced the overall panel conversion efficiency to $20.47 \%$, as per manufacturer data.

The Agro photovoltaic APV approach proved to be feasible in this simulation and the main critical parameters were pointed out. Crop management practices in the sugar-energy sector have been consolidated for years. Any proposed change can understandably be of great questioning. New techniques need to be implemented in pilot plants for the approach proposed here to be proven experimentally. The simulations showed the potential of the approach, even when compared with conventional PV strategies. Agro Photovoltaics can reaffirm the sugar-energy sector as a major producer of renewable energy, an optimizer of land use efficiency. Here is the invitation for managers of the sector to envision this opportunity.

\section{Conclusions}

The Agro photovoltaic approach resulted a promising strategy in the sugar-energy sector, provided that its architectures are adapted to agronomic constraints and the nature of sugarcane activity. It has been shown that the proposed architecture allows exploring synergies and respecting the mutual constraints, and in these cases the approach can earn significantly higher revenues from 
the combined activities. The results suggest that for sugarcane crops, small photovoltaic coverage area around $1.8 \%$ can be advantageous in the combined approach. The results showed significant additional economic gains by electric cogeneration, and improvement of agricultural yields, and optimizing land use, increasing its usage efficiency. It was found that the strategy has an average period of return on investment around 12 years, case of self-equity, and around 9 years for the funded case according to existing state sponsored financial products. The feasibility constraints in cost are those related to the CAPEX of the installation, the price of photovoltaic modules and the inverter, which are strongly linked to the currency exchange ratio. The greatest cost differential was caused by the modifications in the installation of the higher structures required by photovoltaic modules, adapted in appropriate design to allow the correct management of the crop. The price of electricity is the greatest feasibility constraint, being the primary decision flag. The combined venture is feasible for PLD above $\mathrm{R} \$ 230 \mathrm{MWh}^{-1}$. The economic feasibility found justify decision of investments in the development of this technology, whether in pilot plants or at reduced scales, aiming at validating the assumptions and the approach.

How to cite: Stefani, M.A, Felema, J. Agro photovoltaic: feasibility of synergistic system in the sugarcane bioenergy sector. Quaestum. 2022;(3): e26750578.

Author contributions: All authors contributed in Design, Data Collection, Data Analysis, Methodology Definition, Writing and Editing.

\section{References}

[1] Weselek A.; Ehmann A.; Zikeli S. Agrophotovoltaic systems: applications, challenges, and opportunities. A review. Agron Sustain Dev. 2019; Springer-Verlag France.

[2] Goetzberger A.; Zastrow A. Kartoffeln unter dem Kollektor. Sonnenenergie.1981.

[3] Dupraz C.; Marrou H.; Talbot G. 2011. Combining solar photovoltaic panels and food crops for optimising land use: Towards new agrivoltaic schemes. Renew Energ. 2011; 36(10): 2725-2732.

[4] Marrou H.; Dufour L.; Wery J. How does a shelter of solar panels influence water flows in a soil-crop system? Eur J Agron. 2013; 50: 38-51.

[5] Marrou H.; Wery J.; Dufour L.; Dupraz C. Productivity and radiation use efficiency of lettuces grown in the partial shade of photovoltaic panels. Eur J Agron. 2013; 44: 54-66.

[6] Adeh E.H.; Good S.P.; Calaf M.; Higgins C.W. Solar PV Power Potential is Greatest Over Croplands. Sci Rep. 2019; 9(1):1-6.

[7] Harinarayana T.; Vasavi K.S.V. Solar Energy Generation Using Agriculture Cultivated Lands. SGRE. 2014; 5(2): 31-42.

[8] Essam R. Evaluation of agrophotovoltaic technical and economical potential in Egypt including optimization of system technology and harvest. (Dissertation) Giza, Egypt, University of Kassel \& Cairo University. 2014.

[9] Schindele S.; Trommsdorff M.; Schlaak A. Implementation of agrophotovoltaics: Techno-economic analysis of the priceperformance ratio and its policy implications Stephan. Appl Energy. 2020; 265: 114737.

[10] Dias L.; Gouveia J.P.; Lourenço P.; Seixas J. Interplay between the potential of photovoltaic systems and agricultural land use. Land use policy. 2019; 81: 725-735.

[11] Trommsdorff M. An Economic Analysis of Agrophotovoltaics: Opportunities, Risks and Strategies towards a More Efficient Land Use. Constitutional Economics Network. 2016; 03: 35. Available in <https://www.econstor.eu/ bitstream/10419/150976/1/879248831.pdf>.

[12] Bigaton A.; Danelon A.F.; Bressan G.; Silva H.J.T.; Rosa J.H.M. Previsão de custos do setor sucroenergético na região Centro-Sul do Brasil: safra 2017/18. Revista IPecege. 2017; 3(3): 65.

[13] Bigaton A.; Meneghel de Moraes J.M.; Silva H.J.T.; Rosa J.H.M. Evolução de indicadores industriais e custos de produção do setor sucroenergético. Revista IPecege. 2018; 4(2): 77-81.

[14] Dinesh H.; Pearce J.M. The potential of agrivoltaic systems. Renew Sust Energ. 2016; 54: $299-308$.

[15] Amaducci S.; Yin X.; Colauzzi M. Agri voltaic systems to optimize land use for electric energy production. Appl Energy. 2018; 220: 545-561.

[16] Barron-Gafford G.A.; Pavao-Zuckerman M.A.; Minor R.L. Agrivoltaics provide mutual benefits across the food-energywater nexus in drylands. Nat Sustain. 2019; 2(9): 848-855.

[17] Marrou H.; Guilioni L.; Dufour L.; Dupraz C.; Wery J. Microclimate under agrivoltaic systems: Is crop growth rate affected in the partial shade of solar panels? Agric For Meteorol. 2013; 177: 117-132.

[18] Poorter H.; Niinemets U.; Ntagkas N; Siebenkäs A.; Mäenpää M.; Matsubara S.; Pons T. A meta-analysis of plant responses to light intensity for 70 traits ranging from molecules to whole plant performance. New Phytol. 2019; 223(3): 1073-1105. https://doi.org/10.1111/nph.15754.

[19] Rodrigues J.D.; Jadoski Junior C.; Fagan E.B.; Ono E.O.; Soares L.H.; Dourado Neto D. Fisiologia da produção de Cana de Açúcar. Editora ANDREI, São Paulo, SP, Brasil. 2018.

[20] Sage R.F.; Peixoto M.M.; Sage T.L. Photosysthesis in Sugarcane, In: Moore P.H.; Boths F.C, (Ed). Sugarcane: Physiology, Biochemistry and Functional Biology, 1st ed. New Jersey: John Wiley \& Sons; 2014.

[21] Schwerz F.; Medeiros S.L.P.; Elli E.F.; Eloy E.; Sgarbossa J.; Caron B.O. Plant growth, radiation use efficiency and yield of sugarcane cultivatein agroforestry systems: An alternative for threatened ecosystems. An Acad Bras Cienc. 2018; 90(4): 3265-3283.

[22] Agência Nacional de Energia Elétrica (ANEEL). Resolução Normativa no 482, de 17 de abril de 2012. Brasília: ANEEL; 2012.

[23] Agência Nacional de Energia Elétrica (ANEEL). Resolução Normativa no 687 de 2015. Brasília: ANEEL; 2015.

[24] Agência Nacional de Energia Elétrica (ANEEL). Perguntas e Respostas sobre a aplicação da Resolução Normativa no 482/2012 - updated may 25, 2017. Brasília: ANEEL; 2017. Available in https://www.aneel.gov.br/ documents/656827/15234696/FAQ+-V3_20170524/ab9ec474-7dfd-c98c-6753-267852784d86. 
[25] Centro de Referência para Energia Solar e Eólica (CRESESB). Potencial Solar - SunData v 3.0. Rio de Janeiro: CEPEL; 2020. Available in <http://www.cresesb.cepel.br/index.php?section=sundata $>$.

[26] Instituto Pecege (PECEGE). Radar Sucroenergético: Custos de produção de cana-de-açúcar, açúcar, etanol e bio eletricidade na região centro-sul do Brasil: fechamento da safra 2019/2020, Relatório PECEGE Evento Expedição de Custos Cana, updated october, 2020. Available in <https://radarsucroenergetico.com/>.

[27] Associação Brasileira de Energia Solar Fotovoltaica (ABSOLAR). Energia Solar Fotovoltaica: Panorama, oportunidades e desafios, Seminário Desafios da Energia no Brasil, Brasília, 2017. Available in <www.absolar.com.br>.

[28] Greener. Geração Distribuída. Estudo Estratégico: Mercado Fotovoltaico, 2o semestre 2020. 2021. Available in <www. greener.com.br>.

[29] Centro de Comercialização de Energia Elétrica (CCEE). PLD Media Mensal. 2021. Available in <https://www. ccee.org.br/portal/faces/pages_publico/o-que-fazemos/como_ccee_atua/precos/preco_media_mensal?_adf. ctrl-state=kms1i751d_1\&_afrLoop=24486461544925\#!\%40\%40\%3F_afrLoop\%3D24486461544925\%26_adf.ctrlstate\%3Dkms1i751d 5>.

[30] Banco Central do Brasil (BACEN). Preços e taxas dos títulos IPCA, pré e pós-fixados. Tesouro Direto Tesouro IPCA 2045. 2021. Available in <https://www.tesourodireto.com.br/titulos/precos-e-taxas.htm>.

[31] Banco Nacional de Desenvolvimento Econômico e Social (BNDES). FINEM Geração de Energia. 2021. Available in <https://www.bndes.gov.br/wps/portal/site/home/financiamento/produto/bndes-finem-energia>.

[32] Willockx B.; Herteleer B.; Ronsijn B. Uitterhaegen B.; Cappelle J. A standardized classification and performance indicators of agrivoltaic systems. Conference: 37th European Photovoltaic Solar Energy Conference and Exhibition. 2020 1-5. DOI:10.4229/EUPVSEC20202020-6CV.2.47.

[33] Hassanpour E.; Id A.; Selker J. S. Remarkable agrivoltaic influence on soil moisture, micrometeorology, and water-use efficiency. PLoS ONE. 2018; 13(11): e0203256. https:// doi.org/10.1371/journal.pone.0203256.

[34] Schwerz F. Interações dinâmicas no crescimento de tungue e cana-de-açúcar em sistemas agroflorestais. (Dissertation) - Universidade Federal de Santa Maria, Campus de Frederico Westphalen, RS, Brasil. 2017.

[35] Schwerz F.; Elli E.F.; Behling A.; Schmidt D.; Caron B.; Sgarbossa J. Yield and qualitative traits of sugarcane cultivated in agroforestry systems: Toward sustainable production systems. Renew Agric Food Syst. 2017; 34(4): $280-292$.

[36] Caron B.O.; Elli E.F.; Behling A.; Eloy E.; Schmidt D.; Stolzle J. Growth of tree species and sugarcane production in agroforestry systems. An Acad Bras Cienc. 2018; 90(2): 2425-2436.

[37] Elli E.F.; Caron B.O.; De Paula G.M.; Eloy E.; Schwerz F.; Schmidt D. Ecofisiologia da cana-de-açúcar no sub-bosque de canafístula em arranjos de sistema agroflorestal. Com Sci. 2016; 7(4): 464-472.

[38] Pinto F.L.G.; Bernardes M.S.; Sparovek G. Feasibility of Cultivation of Sugarcane in Agroforestry Systems. Sci agric 2019; 60(3): 489-493.

[39] Associação Brasileira de Normas Técnicas (ABNT). ABNT NBR 16690:2019 Instalações Elétricas de arranjos Fotovoltaicos - Requisitos de Projeto. São Paulo: ABNT; 2019

[40] Conselho Nacional do Meio Ambiente (CONAMA). Resolução № 279 de 27 de junho de 2001. Available in <https:// www.normasbrasil.com.br/norma/?id=96891>.

[41] Secretaria de Estado do Meio Ambiente de São Paulo (SMA). Resolução no74/2017 Available at <https://www. infraestruturameioambiente.sp.gov.br/legislacao/2017/08/resolucao-sma-74-2017/>. 